\title{
Adsorptive Removal of Rhodamine B Using Novel Adsorbent-Based Surfactant-Modified Alpha Alumina Nanoparticles
}

\author{
Thi Hai Yen Doan, ${ }^{1}$ Thi Phuong Minh Chu, ${ }^{1}$ Thi Diu Dinh, ${ }^{1}$ Thi Hang Nguyen, ${ }^{1,2}$ \\ Thi Cam Tu Vo, ${ }^{3}$ Nhat Minh Nguyen, ${ }^{3}$ Bao Huy Nguyen, ${ }^{4}$ The An Nguyen, ${ }^{5}$ \\ and Tien Duc Pham iD ${ }^{1}$ \\ ${ }^{1}$ Faculty of Chemistry, University of Science, Vietnam National University, Hanoi - 19 Le Thanh Tong, Hoan Kiem, \\ Hanoi 100000, Vietnam \\ ${ }^{2}$ Department of Infrastructure and Urban Environmental Engineering, Hanoi Architectural University, Nguyen Trai, \\ Thanh Xuan, Hanoi 100000, Vietnam \\ ${ }^{3}$ HUS High School for Gifted Students, University of Science, Vietnam National University, Hanoi, 182 Luong the Vinh, \\ Thanh Xuan, Hanoi 100000, Vietnam \\ ${ }^{4}$ Marie Curie School, Tran van Lai, My Dinh 1, Nam Tu Liem, Hanoi 100000, Vietnam \\ ${ }^{5} 499$ Tran Khat Chan, Hai Ba Trung, Hanoi 100000, Vietnam
}

Correspondence should be addressed to Tien Duc Pham; tienduchphn@gmail.com

Received 6 October 2020; Revised 25 November 2020; Accepted 30 November 2020; Published 9 December 2020

Academic Editor: Pablo Richter

Copyright (c) 2020 Thi Hai Yen Doan et al. This is an open access article distributed under the Creative Commons Attribution License, which permits unrestricted use, distribution, and reproduction in any medium, provided the original work is properly cited.

\begin{abstract}
The objective of the present study is to investigate removal of cationic dye, rhodamine $\mathrm{B}(\mathrm{RhB})$, in water environment using a highperformance absorbent based on metal oxide nanomaterials toward green chemistry. The adsorption of sodium dodecyl sulfate (SDS) onto synthesized alpha alumina $\left(\alpha-\mathrm{Al}_{2} \mathrm{O}_{3}\right)$ material $(M 0)$ at different ionic strengths under low $\mathrm{pH}$ was studied to fabricate a new adsorbent as SDS-modified $\alpha-\mathrm{Al}_{2} \mathrm{O}_{3}$ material (M1). The $\mathrm{RhB}$ removal using $M 1$ was much higher than $M 0$ under the same experimental conditions. The optimal conditions for RhB removal using $M 1$ were found to be contact time $30 \mathrm{~min}$, $\mathrm{pH} 4$, and adsorbent dosage $5 \mathrm{mg} / \mathrm{mL}$. The maximum $\mathrm{RhB}$ removal using $M 1$ achieved $100 \%$, and adsorption amount reached $52.0 \mathrm{mg} / \mathrm{g}$. Adsorption isotherms of $\mathrm{RhB}$ onto $M 1$ were well fitted by the two-step adsorption model. The electrostatic attraction between positive RhB molecules and negatively charged $M 1$ surface controlled the adsorption that was evaluated by the surface charge change with zeta potential and adsorption isotherms. Very high RhB removal of greater than $98 \%$ after four regenerations of $M 1$ and the maximum removal for all actual textile wastewater samples demonstrate that SDS-modified nano $\alpha-\mathrm{Al}_{2} \mathrm{O}_{3}$ is a highperformance and reusable material for RhB removal from wastewater.
\end{abstract}

\section{Introduction}

Rhodamine $\mathrm{B}(\mathrm{RhB})$ has been commonly used as dyes in the industries such as the printings, textiles, papermaking, paints, and leathers [1-3]. A substantial amount of $\mathrm{RhB}$ has been released into the environment, polluting the water and causing danger to the biological systems and human life [4-6]. The characteristics of $\mathrm{RhB}$ are similar with other synthetic aromatic dyes which are difficultly eliminated out of water due to the high water solubility and difficultly degraded by the light, the temperature, the chemicals, and the microbes $[7,8]$. The removal of $\mathrm{RhB}$ is important for the wastewater treatment. The conventional techniques basing on the biochemical, physical, and chemical properties are employed to remove the $\mathrm{RhB}$ from aqueous solution which are photocatalytic degradation $[9,10]$, ion exchange $[11,12]$, 
membrane filtration [13], and adsorption [6, 14, 15]. However, these techniques show some disadvantages such as the low efficiency, the long consumption time, and the nonbiodegradable product generations [1]. Some researchers studied photocatalytic degradation of $\mathrm{RhB}$ from the industrial effluents under the effective factors of the UV radiation, the temperature, the electron acceptor $\mathrm{H}_{2} \mathrm{O}_{2}, \mathrm{pH}$ [10], and the $\mathrm{TiO}_{2}$ dosage $[9,16]$, introducing the high removal efficiency, the low cost, and the low consumption time. However, the photocatalytic degradation process is more potential to handle $\mathrm{RhB}$ from the pretreated wastewater than the raw one [9]. On the other hand, Goto et al. [17] found that the foam separation is one of the most effective methods to remove zwitterionic $\mathrm{RhB}$ from solutions in which $\mathrm{RhB}$ was adsorbed onto a the bubble surface of the surfactant anionic sodium dodecyl sulfate. Moreover, adsorption is the most suitable methods to remove RhB from aqueous solution [7, 8, 18]. The activated carbons have widely applied as adsorbents to remove $\mathrm{RhB}$ due to its simplicity and efficiency [7, 9, 19]. Recently, the activated carbon has been produced from some diversified natural materials such as the orange peels [2], the chestnut peels [20], the resins [12, 14], the almond shells [19], and the palm shells [21]. However, activated carbon is a high-cost material that is not suitable for developing countries [22]. Therefore, many scientists pay more attention in the development of low-cost adsorbents. The RhB can be removed by raw adsorbents or modified-adsorbents. Qin et al. [23] proved that the $\mathrm{Fe}_{3} \mathrm{O}_{4} / \mathrm{RGO}$ composite is more effective for $\mathrm{RhB}$ removal than the activated carbon. The authors also found that the $\mathrm{RhB}$ adsorption on the composites was 3.7 times higher of the adsorption capacity and 30 times faster of the adsorption rate than that is on the active carbon [23]. Selvam et al. [24] mentioned that the sodium montmorillonite was the available and cheap clay for eliminating dyes. The removal of $\mathrm{RhB}$ from the textile effluents was achieved more highly through the adsorption technique using the purified bentonite clays than the natural one due to the smaller diameter particles and the higher proportion of bentonite in the purified clays [25]. The use of the surfactant-modifiedsubstrates to remove $\mathrm{RhB}$ has been proved to be more effective in many studies due to the advantages in modifying the surface properties and the essential surface charge $[26,27]$. The adsorption isotherms of surfactants onto the oppositely charged surface fast reach to an equilibrium state that is useful to modify the adsorbent surface [28]. The high efficiency of RhB removal from aqueous solution was found to be $83.0 \%$ by the adsorption onto the cationic surfactantmodified-bentonite clay at a high $\mathrm{pH}$ of 9.0 [26], or $99.3 \%$ $\mathrm{RhB}$ removal was achieved by using anionic surfactantmodified-zeolite at a $\mathrm{pH}$ of 3 [27]. The adsorption kinetics of $\mathrm{RhB}$ using various adsorbents followed a pseudo-secondorder model [15, 24, 26, 27]. The adsorption kinetics are strongly depended on the substrate surface and the type of surfactant [28].

In our previous research, $\mathrm{RhB}$ was completely removed through the adsorption technique using the anion surfactant sodium dodecyl sulfate (SDS) modified- $\gamma-\mathrm{Al}_{2} \mathrm{O}_{3}$ [29]. Although, $\gamma-\mathrm{Al}_{2} \mathrm{O}_{3}$ has high specific surface area, the $\alpha-\mathrm{Al}_{2} \mathrm{O}_{3}$ is the most stable form [30]. Also, $\alpha-\mathrm{Al}_{2} \mathrm{O}_{3}$ is the main component of the natural soil so that a comprehensive study on $\alpha-\mathrm{Al}_{2} \mathrm{O}_{3}$ is important for further investigation with the real soil. Therefore, the systematically adsorptive removal of $\mathrm{RhB}$ using $\alpha-\mathrm{Al}_{2} \mathrm{O}_{3}$ was used in the present study. The SDS is applied to modify the $\alpha-\mathrm{Al}_{2} \mathrm{O}_{3}$ surface for $\mathrm{RhB}$ removal from the wastewater. The adsorption mechanisms are extensively investigated basing on the charging behaviors of adsorbent and adsorption isotherms. The regeneration of adsorbent and application for $\mathrm{RhB}$ removal from actual textile wastewater samples are also studied in this work.

\section{Materials and Methods}

2.1. Materials. Aluminum nitrate $\left(\mathrm{Al}\left(\mathrm{NO}_{3}\right)_{3} \cdot 9 \mathrm{H}_{2} \mathrm{O}\right)$ and $\mathrm{NaOH}$ pellets, which are analytical reagents, are delivered from Samchun (Korea). Sodium dodecyl sulfate (SDS) (>95\% of purify, Wako Pure Chemical Industries, Ltd., Japan) was directly used without further purification as a surface modifier. The critical micelle concentration (CMC) of SDS is measured by the conductometry under different $\mathrm{NaCl}$ (p. a, Merck, Germany) concentrations at $22^{\circ} \mathrm{C}$ mentioned in somewhere [31]. The stock SDS solution of $0.1 \mathrm{M}$ was prepared for adsorption experiments. Rhodamine $\mathrm{B}(\mathrm{RhB})$ was purchased from Merck with a molecular weight of $479.02 \mathrm{~g} / \mathrm{mol}$, and the purity $>95 \%$ is employed as cationic dye. The chemical structures of SDS surfactants and $\mathrm{RhB}$ were described elsewhere [29]. The ionic strength was controlled by adding the suitable volume of $0.1 \mathrm{M} \mathrm{NaCl}$. The salt solution was filtered through a $0.2 \mu \mathrm{m}$ cellulose membrane before using. The $\mathrm{pH}$ solution is adjusted by the addition of $\mathrm{HCl}$ and $\mathrm{NaOH}$ and measuring by a $\mathrm{pH}$ meter (Hanna, Woonsocket city, USA). Ultrapure water with a resistance of $18.2 \mathrm{M} \Omega . \mathrm{cm}$ used in all experiments was daily produced by an ultrapure water system (Labconco, Kansai, MO, USA).

\subsection{Alpha Alumina Synthesis and Modification.} Nanosized alpha alumina $\left(\alpha-\mathrm{Al}_{2} \mathrm{O}_{3}\right)$ was synthesized by the solvothermal method according to our previously published paper [32]. It should be noted that all alumina forms are transformed to $\alpha-\mathrm{Al}_{2} \mathrm{O}_{3}$ at a temperature of $1200^{\circ} \mathrm{C}$. Therefore, at the final step, the alumina powder was kept at $1200^{\circ} \mathrm{C}$ for $12 \mathrm{~h}$ to from $\alpha-\mathrm{Al}_{2} \mathrm{O}_{3}$ completely before cooling down to room temperature in a desiccator. This material was denoted as $M 0$ adsorbent.

2.3. Modification of $\alpha-\mathrm{Al}_{2} \mathrm{O}_{3}$ by the SDS Adsorption. Prior to each modification experiment, the $\alpha-\mathrm{Al}_{2} \mathrm{O}_{3}$ nanoparticles with the size range from about 30 to $40 \mathrm{~nm}$ (determined by TEM (transmission electron microscopy)) were vigorously mixed for $2 \mathrm{~h}$ by a multiple shaker. Then, the nanoparticles were sonicated for $20 \mathrm{~min}$ to eliminate particle aggregation. The $\alpha-\mathrm{Al}_{2} \mathrm{O}_{3}$ adsorbents were modified by the addition of the appropriate volume of the stock SDS solution. All the adsorption experiments were carried out at $\mathrm{pH} 6$ under the ionic strength condition of $0.01 \mathrm{M} \mathrm{NaCl}$. All samples were 
thoroughly shaked for $2 \mathrm{~h}$ to reach the adsorption equilibrium.

2.4. Adsorptive Removal of $\mathrm{RhB}$ Using $\alpha-\mathrm{Al}_{2} \mathrm{O}_{3}$ and SDSModified $\alpha-\mathrm{Al}_{2} \mathrm{O}_{3}$. The SDS modified $\alpha-\mathrm{Al}_{2} \mathrm{O}_{3}$ was washed with ultrapure water to remove the excess of SDS and to form $M 1$ adsorbent. The $\mathrm{RhB}$ removal using synthesized $\alpha-\mathrm{Al}_{2} \mathrm{O}_{3}(M 0)$ and SDS modified $\alpha-\mathrm{Al}_{2} \mathrm{O}_{3}(M 1)$ was also carried out at room temperature $\left(25 \pm 2^{\circ} \mathrm{C}\right)$ under different conditions of $\mathrm{pH}$, contact time, and adsorption dosage. Each adsorptive removal experiment was carried out at least three times. The RhB concentrations were quantified by ultraviolet visible (UV-Vis) spectroscopy at a wavelength of $554 \mathrm{~nm}$ using a spectrophotometer (UV-1650 PC, Shimadzu, Japan). The limit of detection (LOD) of UV-Vis spectroscopy for Rh determination was found to be $10^{-8} \mathrm{M}$. The removal (\%) of $\mathrm{RhB}$ was determined by

$$
\text { Removal }=\frac{C_{i}-C_{e}}{C_{i}} \times 100 \%,
$$

where $C_{i}$ and $\mathrm{C}_{e}$ are initial and equilibrium concentrations of $\mathrm{RhB}$ (mol/L), respectively.

The adsorption capacities of SDS onto $M 0$ and RhB onto M1 were determined by

$$
\Gamma=\frac{C_{i}-C_{e}}{m} \times M \times 1000,
$$

where $\Gamma$ is the adsorption amount of $\mathrm{RhB}(\mathrm{mg} / \mathrm{g}), \mathrm{C}_{i}$ the initial $\mathrm{RhB}$ concentration $(\mathrm{mol} / \mathrm{L}), C_{e}$ is the equilibrium $\mathrm{RhB}$ concentration (mol/L), $M$ is molecular weight of $\mathrm{RhB}$ $(\mathrm{g} / \mathrm{mol})$, and $m$ is the adsorbent dosage $(\mathrm{mg} / \mathrm{mL})$.

The adsorption isotherms of $\mathrm{RhB}$ onto $M 1$ were fitted by the two-step model with a general isotherm equation. The general isotherm equation [33] is

$$
\Gamma=\frac{\Gamma_{\infty} k_{1} C\left((1 / n)+k_{2} C^{\mathrm{n}-1}\right)}{1+k_{1} C\left(1+k_{2} C^{\mathrm{n}-1}\right)},
$$

where $\Gamma$ is the adsorption amount of RhB at concentration $\mathrm{C}, \Gamma_{\infty}$ is the maximum adsorption capacity, $k_{1}$ and $k_{2}$ are equilibrium constants for in the first and second step, respectively, and $n$ is cluster of adsorption. $C$ is the equilibrium concentration of RhB.

To evaluate the adsorption mechanisms, the change in surface charge was evaluated by monitoring zeta $(\zeta)$ potential. The sample was added into a plastic capillary cell, then inserted in a laser velocimetry setup Zetasizer Nano ZS (Malvern Instruments, UK) under the electric field of $11.3 \mathrm{~V} / \mathrm{cm}$. Each measurement was repeated 3 times with 30 subruns. The $\zeta$ potential was calculated by Smoluchowski's equation [34]:

$$
\zeta=\frac{u_{e} \eta}{\varepsilon_{r s} \varepsilon_{0}},
$$

where $\zeta$ is the zeta potential $(\mathrm{mV}), \mathrm{u}_{e}$ is the electrophoretic mobility $(\mu \mathrm{m} \mathrm{cm} / \mathrm{V} . \mathrm{s}), \eta$ is the dynamic viscosity of the liquid $(\mathrm{mPa} . \mathrm{s}), \varepsilon_{r s}$ is the relative permittivity constant of the electrolyte solution $(\mathrm{F} / \mathrm{m})$, and $\varepsilon_{0}$ is the electric permittivity of the vacuum $\left(8.854 \times 10^{-12} \mathrm{~F} / \mathrm{m}\right)$.

\section{Results and Discussion}

3.1. Adsorption of SDS on the Synthesized $\alpha-\mathrm{Al}_{2} \mathrm{O}_{3}$ Nanoparticles. The charging behavior of synthesized $\alpha-\mathrm{Al}_{2} \mathrm{O}_{3}$ nanoparticles $(M 0)$ after modifying by SDS in the acid media ( $\mathrm{pH} \mathrm{5)}$ and the different ionic strengths is represented in Figure 1. It can be seen that the charge sign of $M 0$ changes and even reverses with the adsorption of anionic SDS. The tendency is consistent with the previous research studies in which the adsorption isotherm of the anionic SDS surfactants takes place into four regions or two steps $[28,35]$. The zeta potential of M0 significantly decreases with the increment of SDS concentration, passing the isoelectric point (IEP), then moving to the saturated state in which the zeta potential keeps constant. In the first region of the low SDS concentration, the zeta potential of $M 0$ decreases slowly until the neutral net charge due to the simple main electrostatic interactions between the anionic surfactants and oppositely charged alumina particles at $\mathrm{pH} 5$. There is a sudden decrement of $\zeta$ potential shown in the second region due to the surfactant aggregation on the $\alpha-\mathrm{Al}_{2} \mathrm{O}_{3}$ surface which is well-known as hemimicelles. The repulsions between SDS surfactants are shielded by the presence of electrolyte ions combining with the hydrocarbon chain forces, resulting in forming the SDS aggregates. In the third region, the surfactant aggregates continue to develop. In the last region, the zeta potential does not change beyond the critical micelle concentration (CMC).

The effect of ionic strength on the SDS adsorption onto $\alpha-\mathrm{Al}_{2} \mathrm{O}_{3}$ nanoparticles is clarified. The $\zeta$ potential of $M 0$ after adsorbing different concentrations of SDS was measured at pH 5 and under two ionic strength conditions. It is shown that at the fixed SDS concentration, the zeta potential of $\alpha-\mathrm{Al}_{2} \mathrm{O}_{3}$ nanoparticles decreases with an increment of the ionic strength from 0.1 to $10 \mathrm{mM}$ of $\mathrm{NaCl}$. The SDS adsorption increased with increasing the $\mathrm{NaCl}$ concentration. The electrolyte ions shield not only the electrostatic forces between anionic SDS surfactants and oppositely charged alumina nanoparticles but also the repulsive forces between SDS surfactant molecules/or between the hemimicelles [36]. Herein, the later effect is stronger than the former one, resulting that more SDS surfactants adsorbed and formed the bilayer of admicelles on the $M 0$ surface [31, 37]. Therefore, the surface charge of $\alpha-\mathrm{Al}_{2} \mathrm{O}_{3}$ remained the highly negatively charged that is useful to remove cationic dye $\mathrm{RhB}$. The use of $0.006 \mathrm{M} \mathrm{SDS}$ at $10 \mathrm{mM} \mathrm{NaCl}$ is suitable to form SDS-modified $\alpha-\mathrm{Al}_{2} \mathrm{O}_{3}(M 1)$ material.

\subsection{Adsorptive Removal of RhB Using Different Adsorbents}

3.2.1. Effect of $p H$. The $\mathrm{pH}$ solution is one of the most important parameter influences to $\mathrm{RhB}$ removal using $M 0$ and $M 1$ materials. The $\mathrm{pH}$ solution strongly influences to the surface charge of adsorbent $M 0$ and the desorption of SDS for modified adsorbent $M 1[31,38]$. The influence of $\mathrm{pH}$ on $\mathrm{RhB}$ removal using $M 0$ and $M 1$ was carried out from $\mathrm{pH} 3$ to 


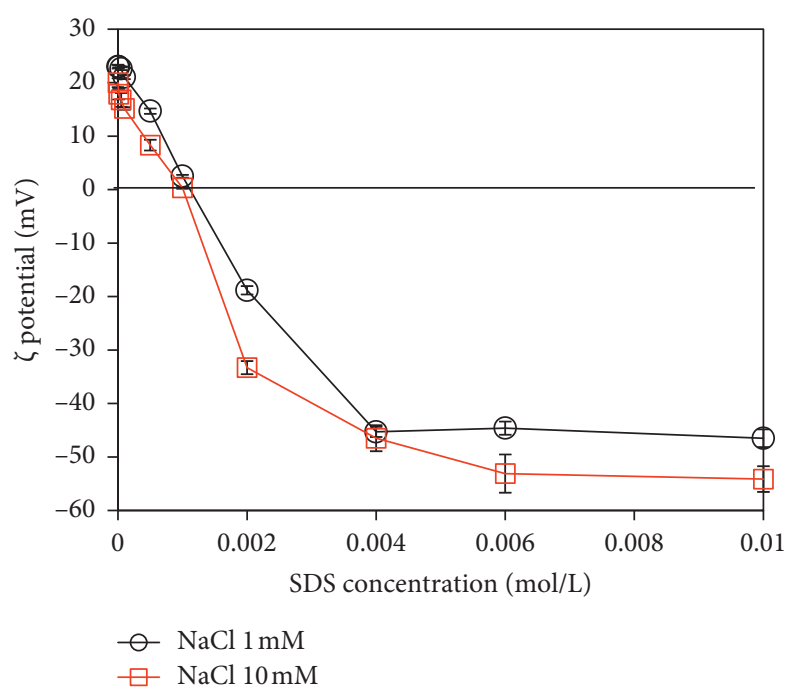

FIgURE 1: The $\zeta$ potential based on adsorption isotherms of the SDS onto $\alpha-\mathrm{Al}_{2} \mathrm{O}_{3}$ nanoparticles at $\mathrm{pH} 5.0$ and under different ionic strengths of 1 and $10 \mathrm{mM} \mathrm{NaCl}$. The standard deviation was taken by the three different measurements.

10 at $1 \mathrm{mM} \mathrm{NaCl}$ using adsorbent dosage of $5 \mathrm{mg} / \mathrm{mL}$, with a contact time of $30 \mathrm{~min}$ (Figure 2).

Figure 2 shows that the $\mathrm{RhB}$ removal using $M 0$ material did not change significantly except for $\mathrm{pH} 4$ in $\mathrm{pH}$ range of 3-10 while the $\mathrm{RhB}$ removal reduced with an increase of $\mathrm{pH}$ from 3 to 10 when using $M 1$ material. At $\mathrm{pH} 3, \alpha-\mathrm{Al}_{2} \mathrm{O}_{3}$ may dissolve into solution so that the error bars show the standard deviations were high for M1 [39]. It should be noted that the M0 surface charge decreases with increasing $\mathrm{pH}$ but the net charge density of $M 0$ is small. Since $\mathrm{RhB}$ is positive charged in the $\mathrm{pH}$ range so that $\mathrm{RhB}$ removal using $M 0$ was rather low (around 25\%). For M1 material, the SDS desorption enhanced with increasing $\mathrm{pH}$ so that the net negative charge of $M 1$ decreased [38]. In all $\mathrm{pH}$ ranges, the $\mathrm{RhB}$ removal using $M 1$ was much higher than that using $M 0$ under the same experimental conditions. Figure 2 also indicates that the RhB removal achieved 95.2 and $32.7 \%$ at $\mathrm{pH} 4$ when using $M 1$ and $M 0$ materials, respectively. Thus, we kept $\mathrm{pH} 4$ for further investigation on RhB removal using both $M 0$ and M1 materials.

3.2.2. Effect of Adsorbent Dosage. For adsorption technique, binding site and specific surface area highly affect the removal efficiency because they can change the surface charge density of adsorbent [40]. The amounts of $M 0$ and $M 1$ materials were changed from 0.5 to $30 \mathrm{mg} / \mathrm{mL}$ (Figure 3). Figure 3 shows that the RhB removal using $M 0$ and $M 1$ materials increased with increasing adsorbent dosage but the RhB removal using $M 1$ achieved the highest efficiency with very small amount of adsorbent. The adsorbent dosage $5 \mathrm{mg} / \mathrm{mL}$ is suitable to get the removal approximately $100 \%$ for $M 1$ while the $\mathrm{RhB}$ removal using M0 was only $26 \%$ with such adsorbent dosage. Thus, optimal adsorbent dosage for $M 1$ was $5 \mathrm{mg} / \mathrm{mL}$.

Because the RhB removal using $M 1$ was extremely higher that using $M 0$, further studies only investigate on the adsorption of RhB onto M1 material.

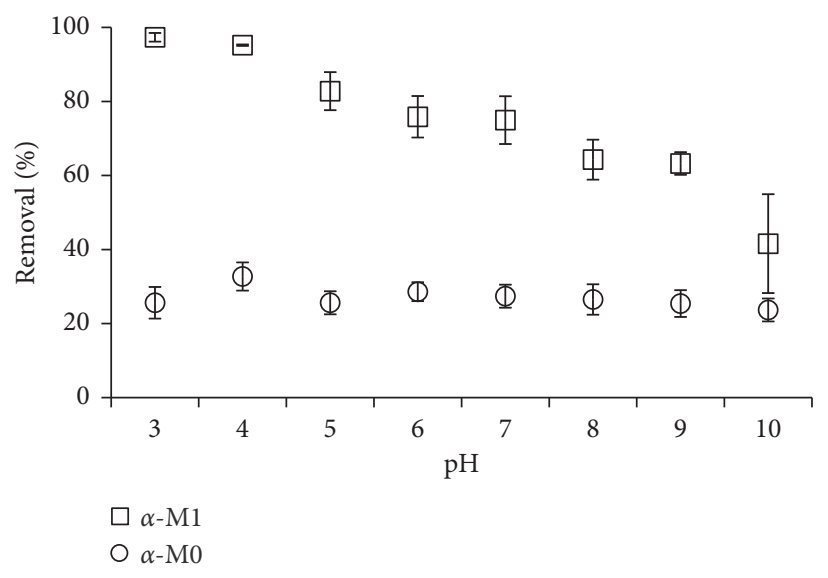

Figure 2: The effect of $\mathrm{pH}$ on $\mathrm{RhB}$ removal using $\alpha-M 0$ and $\alpha-M 1$ materials at $1 \mathrm{mM} \mathrm{NaCl}\left(\mathrm{C}_{i}(\mathrm{RhB})=10^{-5} \mathrm{M}\right.$, adsorbent dosage of $5 \mathrm{mg} / \mathrm{mL}$, and contact time of $30 \mathrm{~min})$.

3.2.3. Effect of Contact Time. Contact time is known as the time from initial mixing $\mathrm{RhB}$ with adsorbent. The $\mathrm{RhB}$ removal using $M 1$ in the contact time range of $0-180 \mathrm{~min}$ is shown in Figure 4.

Figure 4 shows that the contact time for $\mathrm{RhB}$ removal using $M 1$ reached the equilibrium with only $30 \mathrm{~min}$. This time is much faster than $\mathrm{RhB}$ adsorption on well-known adsorbent as activated carbon (120 min) [41]. Therefore, contact time of 30 min was fixed for RhB removal using $M 1$ material.

3.3. Adsorption Mechanisms of RhB onto Synthesized $\alpha-\mathrm{Al}_{2} \mathrm{O}_{3}$ Nanoparticles with SDS Modification (M1). Adsorption isotherms are important to understand adsorption mechanisms of $\mathrm{RhB}$ onto synthesized $\alpha-\mathrm{Al}_{2} \mathrm{O}_{3}$ nanoparticles with SDS modification (M1). Figure 5 shows that at acid media $(\mathrm{pH} 4)$, the adsorption of $\mathrm{RhB}$ at low ionic strength was always higher than at high ionic strength. At high $\mathrm{NaCl}$ 


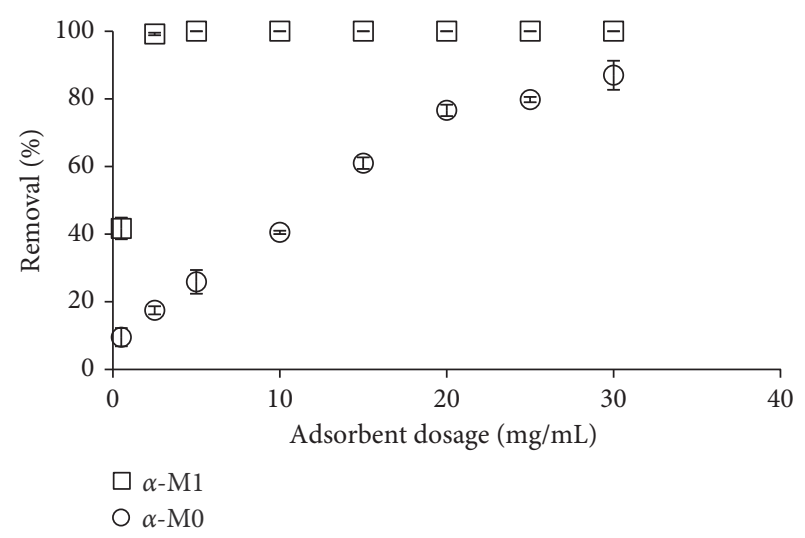

FIgURE 3: The effect of adsorbent dosage on $\mathrm{RhB}$ removal using $\alpha-M 0$ and $\alpha-M 1$ materials at $1 \mathrm{mM} \mathrm{NaCl}\left(\mathrm{C}_{i}(\mathrm{RhB})=10^{-5} \mathrm{M}, \mathrm{pH} 4\right.$, and contact time of $30 \mathrm{~min}$ ).

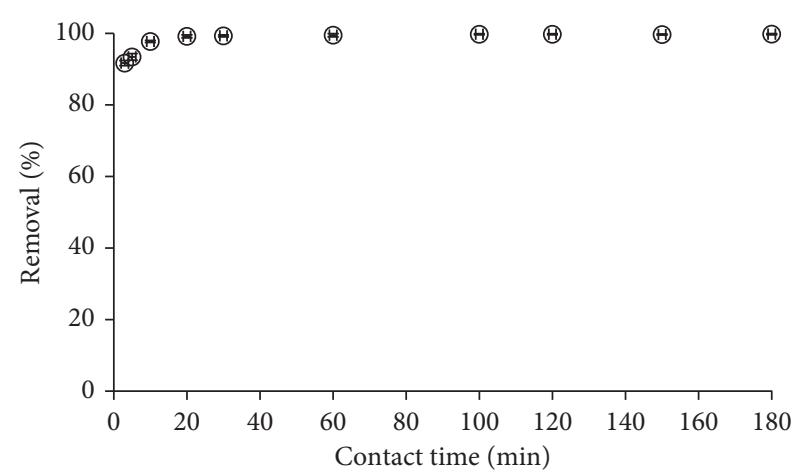

Figure 4: The effect of contact time on RhB removal using $M 1$ material $\left(\mathrm{C}_{i}(\mathrm{RhB})=10^{-5} \mathrm{M}, \mathrm{pH} 4\right.$, and adsorbent dosage $\left.5 \mathrm{mg} / \mathrm{mL}\right)$.

concentration, the total counter ions are high that can screen the surface charge of $M 1$. As a result, the net negative charge of $M 1$ increased (see Figure 1) while the electrostatic attraction between cationic $\mathrm{RhB}$ and negatively charged $M 1$ surface was decreased. We suggest that $\mathrm{RhB}$ adsorption onto $M 1$ is mainly controlled by electrostatic attraction and effect of ionic strength on $\mathrm{RhB}$ adsorption is important.

As can be seen in Figure 5, the data point represented that experimental results of $\mathrm{RhB}$ adsorption onto $M 1$ were in accordance with a two-step adsorption model using the fit parameters in Table 1. Table 1 and Figure 5 show that the plateau $\mathrm{RhB}$ adsorption at $1 \mathrm{mM} \mathrm{NaCl}$ was higher than at $10 \mathrm{mM}$. Interestingly, the same fit parameters of $k_{2}$ and $n$ could be used for two isothermal adsorptions at 1 and $10 \mathrm{mM} \mathrm{NaCl}$. Nevertheless, the $k_{1}$ at $1 \mathrm{mM} \mathrm{NaCl}$ was slightly higher than $k_{1} t$ at $10 \mathrm{mM}$. It implies that the $k_{1}$ can be useful to predict the electrostatic interaction of $\mathrm{RhB}$ adsorption onto SDS-modified $\alpha-\mathrm{Al}_{2} \mathrm{O}_{3}$ nanoparticles. The maximum adsorption capacity of $\mathrm{RhB}$ using $M 1$ materials was found to be $52 \mathrm{mg} / \mathrm{g}$ that was much higher than many reported adsorbents [42].

To confirm the adsorption mechanism, the charging behavior of $\alpha-\mathrm{Al}_{2} \mathrm{O}_{3}$ nanoparticles before and after adsorption was considered. Figure 6 indicates that the $\zeta$

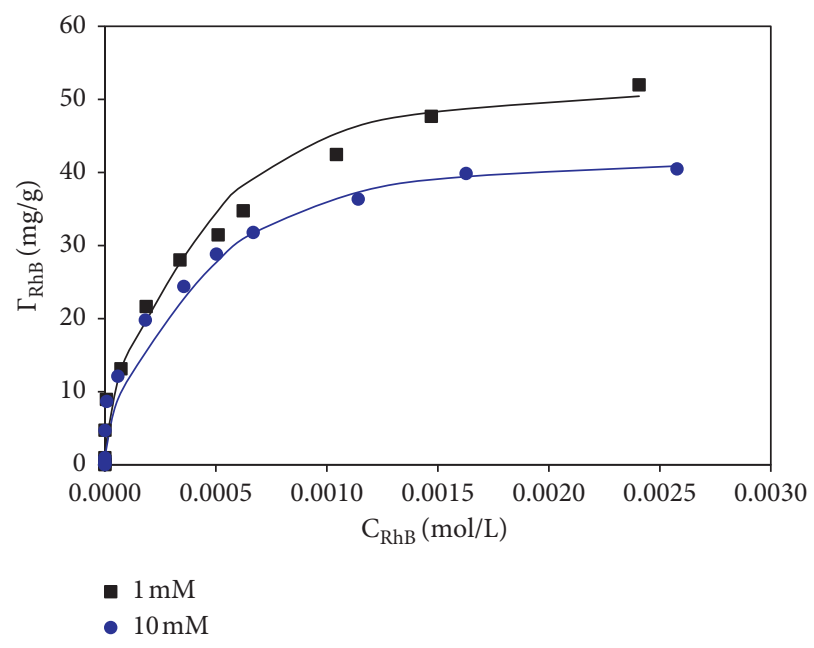

FIgURE 5: Adsorption isotherms of $\mathrm{RhB}$ onto SDS-modified $\alpha-\mathrm{Al}_{2} \mathrm{O}_{3}$ nanoparticles (M1) at two $\mathrm{NaCl}$ concentrations. The points are experimental data while solid lines are fitted by the twostep adsorption model.

potential of synthesized $\alpha-\mathrm{Al}_{2} \mathrm{O}_{3}$ was about $+23.0 \mathrm{mV}$ at $\mathrm{pH}$ 5 . The charge reversal was taken place after SDS adsorption so that a negative charge of $M 1$ was achieved $(\zeta=-53.1 \mathrm{mV})$. Due to the presence of admicelles with local bilayer onto $\alpha-\mathrm{Al}_{2} \mathrm{O}_{3}$ surface, the surface charge of $\alpha-\mathrm{Al}_{2} \mathrm{O}_{3}$ was highly negative. [31, 38]. However, after RhB adsorption, a small positive of $\zeta$ was obtained. The change of $\zeta$ potential indicates that $\mathrm{RhB}$ adsorption onto M1 material was controlled by electrostatic interaction that agrees well with the results of adsorption isotherms. In other word, we can demonstrate that electrostatic is the main driving force that induces $\mathrm{RhB}$ adsorption onto SDS-modified $\alpha-\mathrm{Al}_{2} \mathrm{O}_{3}$ nanoparticles.

3.4. The Reuse Potential and the Application of SDS-Modified Nano $\alpha-\mathrm{Al}_{2} \mathrm{O}_{3}$. The reuse potential of material is needed to examine the stability and regeneration of $M 1$ adsorbent. The M1 absorbent was regenerated by using $0.1 \mathrm{M} \mathrm{NaOH}$. Figure 7 shows the $\mathrm{RhB}$ removal after regeneration cycles. It is clear to observe that the $\mathrm{RhB}$ removal changed insignificantly after four regenerations. The RhB removal was still higher than $98 \%$, indicating that $M 1$ adsorbent-based SDSmodified nano $\alpha-\mathrm{Al}_{2} \mathrm{O}_{3}$ was highly reusable and high performance of $\mathrm{RhB}$ removal.

The application $M 1$ adsorbent in wastewater samples is important to evaluate the performance of adsorbent. The wastewater samples of a textile company in the Pho Noi industrial zone in Hung Yen Province, Vietnam, were collected at three different discharged locations and analyzed in the same day. Then, the textile samples were centrifuged to remove the solids and the solutions were collected. $\mathrm{RhB}$ in each textile wastewater sample was removed under optimal conditions. Table 2 shows the $\mathrm{RhB}$ removal from three wastewater samples using $M 1$ adsorbent. Although the RhB removal is strongly influenced by many factors in actual samples, the RhB removal in all samples reached about $100 \%$. Our results again indicate that SDS-modified nano 
TABLE 1: The fit parameters for adsorption RhB onto SDS-modified $\alpha-\mathrm{Al}_{2} \mathrm{O}_{3}(M 1)$.

\begin{tabular}{lcccc}
\hline$C_{\mathrm{NaCl}}(\mathrm{mM})$ & $\Gamma(\mathrm{mg} / \mathrm{g})$ & $k_{1}\left(10^{3} \mathrm{~g} / \mathrm{mg}\right)$ & $k_{2}\left(10^{3} \mathrm{~g} / \mathrm{mg}\right)^{\mathrm{n}-1}$ & $\mathrm{n}$ \\
\hline 10 & 42 & 25 & 2000 & 2.9 \\
1 & 52 & 30 & 2000 & 2.9 \\
\hline
\end{tabular}

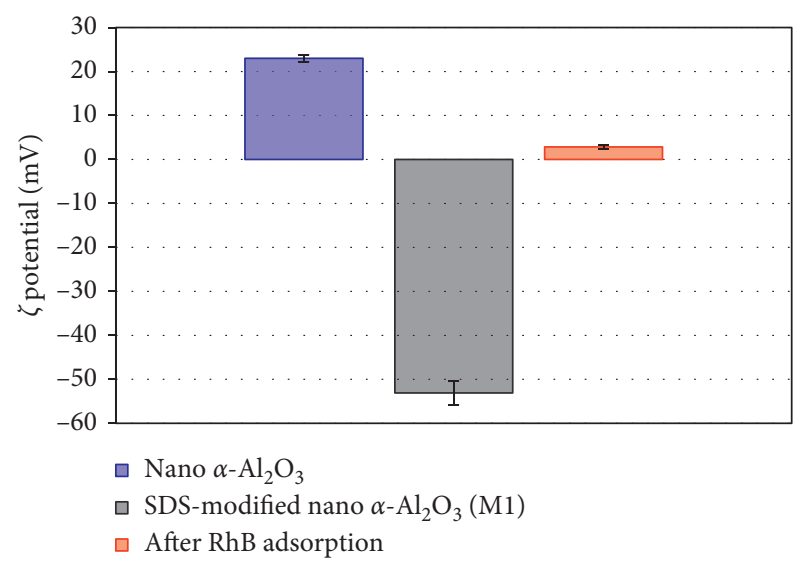

Figure 6: The $\zeta$ potential of synthesized nano $\alpha-\mathrm{Al}_{2} \mathrm{O}_{3}$, SDSmodified nano $\alpha-\mathrm{Al}_{2} \mathrm{O}_{3}(M 1)$, and $M 1$ after $\mathrm{RhB}$ adsorption in $10 \mathrm{mM} \mathrm{NaCl}(\mathrm{pH}$ ).

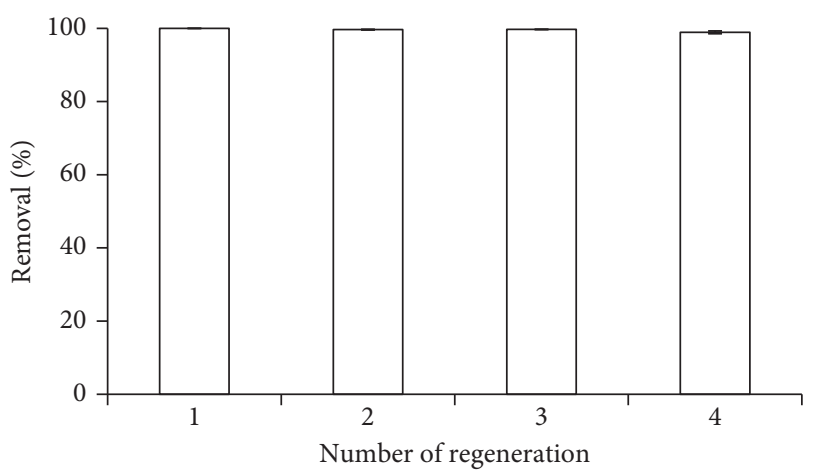

Figure 7: Removal of RhB using M1 after four regenerations. Error bars show standard deviation of three replicates.

TABLE 2: The removal of RhB from textile wastewater using SDSmodified nano $\alpha-\mathrm{Al}_{2} \mathrm{O}_{3}$.

\begin{tabular}{lccc}
\hline $\begin{array}{l}\text { Wastewater } \\
\text { sample }\end{array}$ & $\begin{array}{c}\text { RhB concentration } \\
\text { before treatment } \\
\left(\times 10^{6} \mathrm{M}\right)\end{array}$ & $\begin{array}{c}\text { RhB } \\
\text { concentration } \\
\text { after treatment } \\
(\mathrm{M})\end{array}$ & $\begin{array}{c}\text { Removal } \\
(\%)\end{array}$ \\
\hline S1 & 5.7 & $<$ LOD & $\sim 100$ \\
S2 & 10.5 & $<$ LOD & $\sim 100$ \\
S3 & 10.6 & $<$ LOD & $\sim 100$ \\
\hline
\end{tabular}

$\alpha-\mathrm{Al}_{2} \mathrm{O}_{3}$ is a high-performance adsorbent for the cationic dye removal from wastewater.

\section{Conclusions}

We have reported a scientific research on the $\mathrm{RhB}$ removal using synthesized $\alpha-\mathrm{Al}_{2} \mathrm{O}_{3}$ nanomaterial with surface modification by anionic surfactant SDS. The RhB removal using SDS-modified $\alpha-\mathrm{Al}_{2} \mathrm{O}_{3}$ was much higher than raw $\alpha-\mathrm{Al}_{2} \mathrm{O}_{3}$. The suitable parameters for $\mathrm{RhB}$ removal using SDS-modified $\alpha-\mathrm{Al}_{2} \mathrm{O}_{3}$ were contact time $30 \mathrm{~min}, \mathrm{pH} 4$, and adsorbent dosage $5 \mathrm{mg} / \mathrm{mL}$. The maximum adsorption capacity of $\mathrm{RhB}$ was found to be $52.0 \mathrm{mg} / \mathrm{g}$ while the removal reached $100 \%$. Adsorption isotherms of $\mathrm{RhB}$ onto SDSmodified $\alpha-\mathrm{Al}_{2} \mathrm{O}_{3}$ were in accordance with the two-step adsorption model. Based on the change in surface charge monitoring by zeta potential and adsorption isotherm, we indicate that electrostatic attraction was the main driving force induced adsorption. The SDS-modified $\alpha-\mathrm{Al}_{2} \mathrm{O}_{3}$ is reusable adsorbent for $\mathrm{RhB}$ removal with very high efficiency of greater than $98 \%$ after four regeneration cycles while the $\mathrm{RhB}$ removal using the this adsorbent reached to about $100 \%$ for actual textile wastewater.

\section{Data Availability}

The data and supporting materials are included within the article.

\section{Conflicts of Interest}

The authors declare that there are no conflicts of interest regarding the publication of this paper.

\section{References}

[1] C. Lops, A. Ancona, K. Di Cesare et al., "Sonophotocatalytic degradation mechanisms of Rhodamine B dye via radicals generation by micro- and nano-particles of $\mathrm{ZnO}$," Applied Catalysis B: Environmental, vol. 243, pp. 629-640, 2019.

[2] M. Arami, N. Y. Limaee, N. M. Mahmoodi, and N. S. Tabrizi, "Removal of dyes from colored textile wastewater by orange peel adsorbent: equilibrium and kinetic studies," Journal of Colloid and Interface Science, vol. 288, no. 2, pp. 371-376, 2005.

[3] N. Pourreza, S. Rastegarzadeh, and A. Larki, "Micelle-mediated cloud point extraction and spectrophotometric determination of rhodamine B using Triton X-100," Talanta, vol. 77, no. 2, pp. 733-736, 2008.

[4] S. Madhav, A. Ahamad, P. Singh, and P. K. Mishra, "A review of textile industry: wet processing, environmental impacts, and effluent treatment methods," Environmental Quality Management, vol. 27, no. 3, pp. 31-41, 2018.

[5] M. Ali and T. R. Sreekrishnan, "Aquatic toxicity from pulp and paper mill effluents: a review," Advances in Environmental Research, vol. 5, no. 2, pp. 175-196, 2001.

[6] H. KaurRajvir and K. Kaur, "Removal of Rhodamine-B dye from aqueous solution onto Pigeon Dropping: adsorption, kinetic, equilibrium and thermodynamic studies," Journal of Materials and Environmental Science , vol. 5, pp. 1830-1838, 2014.

[7] V. D. S. Lacerda, J. B. Lopez-Sotelo, A. Correa-Guimaraes et al., "Rhodamine B removal with activated carbons obtained from lignocellulosic waste," Journal of Environmental Management, vol. 155, pp. 67-76, 2015.

[8] F. Li, Y. Chen, H. Huang, W. Cao, and T. Li, "Removal of rhodamine B and $\mathrm{Cr}(\mathrm{VI})$ from aqueous solutions by a polyoxometalate adsorbent," Chemical Engineering Research and Design, vol. 100, pp. 192-202, 2015. 
[9] R. Jain, M. Mathur, S. Sikarwar, and A. Mittal, "Removal of the hazardous dye rhodamine B through photocatalytic and adsorption treatments," Journal of Environmental Management, vol. 85, no. 4, pp. 956-964, 2007.

[10] F. H. AlHamedi, M. A. Rauf, and S. S. Ashraf, "Degradation studies of Rhodamine B in the presence of UV/H2O2," Desalination, vol. 239, no. 1-3, pp. 159-166, 2009.

[11] S. Raghu and C. Ahmed Basha, "Chemical or electrochemical techniques, followed by ion exchange, for recycle of textile dye wastewater," Journal of Hazardous Materials, vol. 149, no. 2, pp. 324-330, 2007.

[12] J. Yang, S. Yu, W. Chen, and Y. Chen, "Rhodamine B removal from aqueous solution by CT269DR resin: static and dynamic study," Adsorption Science \& Technology, vol. 37, no. 9-10, pp. 709-728, 2019.

[13] J. Wu, M. A. Eiteman, and S. E. Law, "Evaluation of membrane filtration and ozonation processes for treatment of reactive-dye wastewater," Journal of Environmental Engineering, vol. 124, no. 3, p. 272, 1998.

[14] S. M. Al-Rashed and A. A. Al-Gaid, "Kinetic and thermodynamic studies on the adsorption behavior of Rhodamine B dye on Duolite C-20 resin," Journal of Saudi Chemical Society, vol. 16, no. 2, pp. 209-215, 2012.

[15] A. Thakur and H. Kaur, "Response surface optimization of Rhodamine B dye removal using paper industry waste as adsorbent," International Journal of Industrial Chemistry, vol. 8, no. 2, pp. 175-186, 2017.

[16] J. O. Carneiro, A. P. Samantilleke, P. Parpot et al., "Visible light induced enhanced photocatalytic degradation of industrial effluents (rhodamine B) in aqueous media using TiO2 nanoparticles," Journal of Nanomaterials, vol. 2016, Article ID 4396175, 13 pages, 2016.

[17] Y. Goto, Y. Nema, and K. Matsuoka, "Removal of zwitterionic rhodamine B using foam separation," Journal of Oleo Science, vol. 69 , no. 6, pp. 563-567, 2020.

[18] A. A. Inyinbor, F. A. Adekola, and G. A. Olatunji, "Adsorption of rhodamine B dye from aqueous solution on irvingia gabonensis biomass: kinetics and thermodynamics studies," South African Journal of Chemistry, vol. 68, pp. 115-125, 2015.

[19] N. Abdolrahimi and A. Tadjarodi, "Adsorption of rhodamineB from aqueous solution by activated carbon from almond shell," Proceedings, vol. 41, no. 1, p. 51, 2019.

[20] T. A. Khan, M. Nazir, and E. A. Kha, "Adsorptive removal of rhodamine B from textile wastewater using water chestnut (Trapa natans L.) peel: adsorption dynamics and kinetic studies," Toxicological and Environmental Chemistry, vol. 95, 2013.

[21] M. Mohammadi, A. J. Hassani, A. R. Mohamed, and G. D. Najafpour, "Removal of rhodamine B from aqueous solution using palm shell-based activated carbon: adsorption and kinetic studies," Journal of Chemical and Engineering Data, vol. 55, no. 12, pp. 5777-5785, 2010.

[22] A. A. Inyinbor, F. A. Adekola, and G. A. Olatunji, "Liquid phase adsorptions of Rhodamine B dye onto raw and chitosan supported mesoporous adsorbents: isotherms and kinetics studies," Applied Water Science, vol. 7, no. 5, pp. 2297-2307, 2017.

[23] Y. Qin, M. Long, B. Tan, and B. Zhou, "RhB adsorption performance of magnetic adsorbent $\mathrm{Fe} 3 \mathrm{O} 4 / \mathrm{RGO}$ composite and its regeneration through A fenton-like reaction," NanoMicro Letters, vol. 6, no. 2, pp. 125-135, 2014

[24] P. P. Selvam, S. Preethi, P. Basakaralingam, N. N. Thinakaran, A. Sivasamy, and S. Sivanesan, "Removal of rhodamine B from aqueous solution by adsorption onto sodium montmorillonite," Journal of Hazardous Materials, vol. 155, no. 1-2, pp. 39-44, 2008.

[25] J. F. D. Neto, I. D. S. Pereira, V. C. D. Silva, H. C. Ferreira, G. D. A. Neves, and R. R. Menezes, "Study of equilibrium and kinetic adsorption of rhodamine B onto purified bentonite clays," Ceramica, vol. 64, pp. 598-607, 2018.

[26] T. S. Anirudhan and M. Ramachandran, "Adsorptive removal of basic dyes from aqueous solutions by surfactant modified bentonite clay (organoclay): kinetic and competitive adsorption isotherm," Process Safety and Environmental Protection, vol. 95, pp. 215-225, 2015.

[27] A. A. AbdulRazak and S. Rohani, "Sodium dodecyl sulfatemodified $\mathrm{Fe} 2 \mathrm{O} 3 /$ molecular sieves for removal of rhodamine $\mathrm{B}$ dyes," Advances in Materials Science and Engineering, vol. 2018, Article ID 3849867, 10 pages, 2018.

[28] S. Paria and K. C. Khilar, "A review on experimental studies of surfactant adsorption at the hydrophilic solid-water interface," Advances in Colloid and Interface Science, vol. 110, no. 3, pp. 75-95, 2004.

[29] T. Chu, N. Nguyen, T. Vu et al., "Synthesis, characterization, and modification of alumina nanoparticles for cationic dye removal," Materials, vol. 12, no. 3, p. 450, 2019.

[30] S. Singh, V. C. Srivastava, T. K. Mandal, and I. D. Mall, "Synthesis of different crystallographic $\mathrm{Al}_{2} \mathrm{O}_{3}$ nanomaterials from solid waste for application in dye degradation," $R S C$ Advances, vol. 4, no. 92, pp. 50801-50810, 2014.

[31] T. D. Pham, M. Kobayashi, and Y. Adachi, "Adsorption of anionic surfactant sodium dodecyl sulfate onto alpha alumina with small surface area," Colloid and Polymer Science, vol. 293, no. 1, pp. 217-227, 2015.

[32] N. T. Nguyen, T. H. Dao, T. T. Truong, T. M. T. Nguyen, and T. D. Pham, "Adsorption characteristic of ciprofloxacin antibiotic onto synthesized alpha alumina nanoparticles with surface modification by polyanion," Journal of Molecular Liquids, vol. 309, p. 113150, 2020.

[33] B.-Y. Zhu and T. Gu, "Surfactant adsorption at solid-liquid interfaces," Advances in Colloid and Interface Science, vol. 37, no. 1-2, pp. 1-32, 1991.

[34] A. V. Delgado, F. Gonzalez-Caballero, R. J. Hunter, L. K. Koopal, and J. Lyklema, "Measurement and interpretation of electrokinetic phenomena," Journal of Colloid and Interface Science, vol. 309, no. 2, pp. 194-224, 2007.

[35] R. Zhang and P. Somasundaran, "Advances in adsorption of surfactants and their mixtures at solid/solution interfaces," Advances in Colloid and Interface Science, vol. 123-126, pp. 213-229, 2006.

[36] J. Zhang, Y. Meng, Y. Tian, and X. Zhang, "Effect of concentration and addition of ions on the adsorption of sodium dodecyl sulfate on stainless steel surface in aqueous solutions," Colloids and Surfaces A: Physicochemical and Engineering Aspects, vol. 484, pp. 408-415, 2015.

[37] T. D. Pham, T. T. Tran, V. A. Le, T. T. Pham, T. H. Dao, and T. S. Le, "Adsorption characteristics of molecular oxytetracycline onto alumina particles: the role of surface modification with an anionic surfactant," Journal of Molecular Liquids, vol. 287, Article ID 110900, 2019.

[38] T. D. Pham, T. T. Do, V. L. Ha et al., "Adsorptive removal of ammonium ion from aqueous solution using surfactantmodified alumina," Environmental Chemistry, vol. 14, no. 5, pp. 327-337, 2017.

[39] G. Lefevre, M. Duc, and M. Fedoroff, "Effect of solubility on the determination of the protonable surface site density of oxyhydroxides," Journal of Colloid and Interface Science, vol. 269, no. 2, pp. 274-282, 2004. 
[40] F. Mazloomi and M. Jalali, "Ammonium removal from aqueous solutions by natural Iranian zeolite in the presence of organic acids, cations and anions," Journal of Environmental Chemical Engineering, vol. 4, no. 2, pp. 1664-1673, 2016.

[41] K. Kadirvelu, C. Karthika, N. Vennilamani, and S. Pattabhi, "Activated carbon from industrial solid waste as an adsorbent for the removal of Rhodamine-B from aqueous solution: kinetic and equilibrium studies," Chemosphere, vol. 60, no. 8 , pp. 1009-1017, 2005.

[42] T. D. Pham, T. T. Pham, M. N. Phan, T. M. V. Ngo, V. D. Dang, and C. M. Vu, "Adsorption characteristics of anionic surfactant onto laterite soil with differently charged surfaces and application for cationic dye removal," Journal of Molecular Liquids, vol. 301, p. 112456, 2020. 